\title{
The teaching situation of the department of English in the universities of Bangladesh: a critical evaluation
}

\author{
Md. Ruhul Amin \\ NPI University of Bangladesh \\ ruhulamin@npiub.edu.bd
}

\begin{abstract}
It has a long history of teaching English literature and language in this sub-continent. The European colonial rulers introduced this teaching with the motive of serving their own purpose, but paradoxically this teaching has benefited the people of this soil as well in many ways. From the very beginning, the English department of any college or university has been treated as one of the most prestigious departments that have produced the best citizens of this soil. But recently the teaching scenario of these departments in Bangladesh is being severely affected owing to different kinds of changes that have occurred in the social and academic arenas of the country. It is now the demand of the present time that the English departments of the universities of our country should take proper steps to address those problems properly and bring back its reputation. The present study attempts to find out the problems that are affecting the teaching and learning process of these departments and thereby damaging the glory and reputation of them, and also to provide some suggestions to cope with those problems.
\end{abstract}

Key words: Department, English language, problem, teaching, literature, universities.

\section{Introduction}

English education began in the Indo-Bangladesh-Pakistan subcontinent through the promulgation of the English Education Act of 1835 during the rule of the East India Company. It was actually Macaulay who, as a member of the committee assigned to promulgate that Act, insisted that English, instead of Persia, which was the language of government during the rules of the Moguls and which was still being used as the official language, or any vernacular, ought to be used as the language of government, education and advancement, and that the great object of the government of the Company should be to promote the European literature and science among the Indians rather than promoting the Oriental or native literature and education. After that, all the funds that were supposed to be spent by the then government for the purpose of promoting the education of the natives began to be utilized for "imparting to the native population knowledge of English literature and science through the medium of the English language" (Aggarwal 1984 cited in Krishnaswamy and Sriraman 1995).

However, the establishment of universities in Calcutta, Bombay and Madras in 1857 can be considered as the landmark in the history of teaching English literature since through the establishment of these universities wider scope was created for it in this subcontinent. The scope was further enhanced when, with the passage of time, some other universities were also established in the different parts of the undivided India under British rule. Obviously, one of them was the University of Dhaka, being established in 1921, and it was the only university in this part, the East Bengal of the undivided India. After the partition of India in 1947, during the Pakistan period four more universities were established in this part, the then East Pakistan.

It is true that one of the motives of Macaulay behind his insistence on making English the medium of education was, according to Serajul Islam Choudhury (2001), "to create through this education a class of natives who, despite their color and blood, would be English in culture and be able to serve as interpreters between the rulers and the millions the English were destined to rule"; but despite the ill-motivated of Macaulay, English education in general and English literature in particular paradoxically proved very helpful in creating the Indian nationalistic feelings in the minds of learners. "Many of the great Indian nationalist leaders of the late $19^{\text {th }}$ and early $20^{\text {th }}$ centuries were well versed in English democratic literature" (K. Chowdhury 1986). What is more, the study of English literature from the very beginning has nourished our emotional and intellectual life, and has helped in a large measure to shape our culture, our taste and also our native language and literature. It is because of this reason that English literature has always been treated as a very 
prestigious, broad, liberal and sophisticated discipline in this sub-continent which, as Ahmed (1986) has opined, "Should train sensibility and intelligence" and which, according to him, "has drawn some of our best minds." Therefore, all the experts and lovers of English language and literature have always put emphasis on its effective teaching so that it can produce such citizens as it is supposed to do.

In the independent Bangladesh at present there are 39 public universities and 93 private universities. Among them, near about two dozen public universities and a larger number of private universities have their English departments, apart from the English departments of the university-level-colleges under the National University. At the very beginning, the English departments of the early-established universities of our country dealt with only English Literature, but the present scenario of them is not the same. The syllabuses of these departments, like those of the English department of the newly-established universities, now include some English language related courses along with the courses in English literature. But the teaching-learning scenario of the Departments of English of the universities of our country is not now as glorious as it was in the past. Undoubtedly, there are some obvious reasons for it, which need to be identified. Nobody can deny that with the passage of time many changes have occurred in the areas of learners' needs, their efficiency in English language, competence of teachers, availability of technology, teaching methodology, teaching-learning aids, etc. The English departments, therefore, need to take into account the changed situation and to adopt the appropriate measures to uphold the prestige and glory that they have inherited from the past. With this end in view, the present study has dealt with the following two research questions:

1. What are the problems the English departments of the universities of Bangladesh are now suffering from?

2. What are the solutions to these problems?

\section{The Problems with the Teaching of English Literature:}

As it has been mentioned in the previous section, with the passage of time many changes have occurred in the different areas relating to the teaching-learning activities of the English departments of the universities of Bangladesh.
Undoubtedly, these changes have led to some significant mismatches or disharmonies with the age-old teaching-learning practices of these departments. Consequently, the English departments are going through some severe problems. If we take a critical view of these problems, we see that they can be divided into four major categories in the broad sense and they are: (1) the lack of linguistic competence of students, (2) the inappropriateness of syllabuses, (3) the inappropriateness of teaching methodology and (4) the lack of teachers' training and their research activities. It should be mentioned that in identifying the problem areas only the academic aspects have been taken into account. Therefore, the discussion of the present study has been kept confined only to these areas.

\subsection{The Lack of Competence of the Students coming to Study English Literature}

Of all the problems mentioned above, the most acute one is the quality of the students who are coming to the English departments of the universities of Bangladesh for studying English literature. Though they are coming to these departments after completing their primary, secondary and higher secondary levels of education, they are found to be linguistically poor and, therefore, quite ineligible for bearing the linguistic load on the subject. Referring to this miserable condition of the linguistic competence of the students who get admission to the Department of English of Dhaka University, Alam (2001) says, “... something had gone drastically wrong with the English being taught in our school and colleges: the majority of the students coming into the department from these institutions were unable to read, write, or speak English with any fluency." Relevantly it can be mentioned here that the standard of English education in our country began to fall from the time when the status of English was relegated from second language to foreign language in the early seventies of the last century after the independence of the country. According to Jalil (1986), "This relegation of English to the position of a foreign language largely accounts for students' lack of motivation to learn it." He opines that two factors are very important for the effective learning of English --- one is learners' exposure to it and another is their motivation to learn it. After the degradation of the status of English of a second language to a foreign language, these two factors suffered a setback, resulting in the heavy damage to the learning of this language in this country. The 
adverse consequence of the degradation of the status of English in our country has also been reported by Professor Aali Areefur Rahman (2008). Referring to the circumstances of teaching English literature in the Department of English at Rajshahi University in the mid-70s Prof. Rahman says, "Students began to arrive in the Department who were extremely deficient in English language." It should be mentioned that the standard of English education went down further when upholding our nationalistic sentiments our government promulgated the "Bengali introduction Law" in 1983, making it compulsory to use Bengali in all spheres of our national life, except in case of communication with foreign governments, countries and organizations."The consequences began to be felt in all sectors, especially in the field of higher education. English was no longer a compulsory medium of instruction and adequate attention to the teaching of English was not given at lower levels" (A.M.M.H. Rahman 1999). However, in the second half of the last nineties, there was an attempt to improve the quality of English education by introducing the Communicative Language Teaching (CLT) approach, but the attempt went in vain owing to some of the faulty decisions in the name of CLT, if considered from our own contextual point of view. It was a great blunder on the part of the English language teaching (ELT) experts or the ELT decision-makers of our country, not to take into consideration the realities of local context and culture while determining the classroom procedures to be followed in teaching English language. The English textbooks that were written at that time embodying these procedures for secondary and higher secondary levels of education have not proved effective. These textbooks contain various types of classroom activities, but many of them remain unpracticed as they do not match with the situational and cultural realities of our country. Another great blunder that was made at that time was the decision of stopping the teaching of English grammar at the lower levels of our education without taking into account the fact that ours is a foreign language context. It can be mentioned that this blunder continued to exist for more than a decade. Consequently, the students of the lower levels of our education immensely suffered from the absence of overt grammar for learning English properly for a long period. It is true that the teaching of English grammar has recently been reintroduced, but the damage that has already been done will take time to be repaired.
Because of their linguistic deficiency, the students of the English department, excepting a limited number of them, find it very difficult to understand the language of their literary texts and are quite unable to appreciate the subtle, rhetoric and intellectual issues of those texts. It is for this reason, teaching a subject like English Literature that demands linguistic sophistication from students has turned to be a very difficult job for the teachers. They very often find themselves in a very awkward situation and helpless in the classroom when they do not get the expected response from their students in spite of their sincere and earnest efforts. In such circumstances, they 'fall upon the thorns of life' or 'bleed'. Referring to this situation, Dutta (2001) says,

"Often in a First Year B. A. Honors class we find ourselves in a difficult situation when we try to introduce English literature to a large number of students, linguistically unprepared and conceptually unequipped." On the other side of the coin, it is found that the linguistically handicapped students feel frustrated when the language of their textbooks appear to be obscure to them or when they fail to properly comprehend what their teachers say in the classroom. As a result, a significant number of them fall victim to dropouts every year and among the rest who somehow survive the linguistic challenge of studying English literature another significant number of them get a very poor grade in the examinations.

\subsection{The Inappropriate Syllabus(es)}

As to the problems with the syllabuses, it can be said that the syllabuses that are followed in the English departments of our public universities are more or less sane, and they traditionally include mainly the classical works of British literature. The works of Geoffrey Chaucer, Francis Bacon, Edmund Spenser, John Donne, Addison, Steel, William Shakespeare, Christopher Marlow, John Milton, Dryden, Ben Jonson, Alexander Pope, William Wordsworth, John Keats, P.B. Shelley, Alfred Tennyson, Robert Browning, D. H. Lawrence, Charles Dickens, Thomas Hardy and many others have been included in the syllabuses generation after generation. However, these syllabuses, in addition to the works of British writers, also include a number of famous works of American writers and poets along with some other classical works that have been translated into English from other languages. Some of these American writers and poets are Walt Whitman, Emily Dickinson, Robert 
Frost, Nathaniel Hawthorne, Mark Twain, Eugene O'Neill, Ernest Hemingway, etc., and among the writers of other languages, the names of Homer, Virgil, Aeschylus, Sophocles, Leo Tolstoy, etc. are worthy of special mention. Very recently, these syllabuses have started including some literary works written by non-native English writers. However, these syllabuses are still dominated by classical and canonical works that are written or translated by the native English writers, and they appear to be 'too heavy' for the students who are linguistically immature. What is more, in addition to these literary works these syllabuses contain a significant number of courses on ELT (English Language Teaching), linguistics, computer science, Bangla literature, etc., thereby making the already 'heavy load' 'heavier' for the linguistically weak students. The situation has been aggravated by the introduction of the semester system into all the universities, except a few numbers of old and big ones. Referring to such type of syllabuses, Alam (2001) has termed them 'notorious' for 'putting the most earnest students to sleep' or 'driving her/him to distraction.' Krishnaswamy and Sriraman (1995) have given a description of the similar kind of situation of teaching English literature in India and have remarked, "No one reads the original texts that are prescribed, neither teachers nor learners, and yet we talk about 'experiencing' great literature!" It can be said that the remark made by Krishnaswamy and Sriraman regarding English literature teaching in India is equally true in our country.

Relevantly, it should be mentioned that in the current semester system the English department of every university, only with a few exceptions, has eight semesters in a four-year Honors programme, with two semesters per year. Within this span of 4 years, students have to complete at least 42 courses consisting of 126 credits. Though literally/apparently every semester is comprised of six months, virtually students do not get more than three and a half months' time for classes as the remaining part of the time is generally spent for the holding of examinations and other relevant purposes. Significantly, in maximum cases each of these courses contains a number of textbooks, presumably four to five ones on an average, which ultimately raises the total number of texts for a semester to a big one. What I want to argue is that compared with the previous time, a syllabus of the English department (especially in the newly established universities) of the present time include a much larger amount of textbooks. Previously, in the traditional system or even in the yearly system of the Honors program of three-year duration, the volume of a syllabus was not more than the half of the present one. Even the two-year Masters' program of the past did not deal with more courses than the one-year Masters' program of the present time does in its two semesters. Therefore, the reality is that the present syllabus of an English department has become 'too heavy to carry' for the linguistically weak students. To put it in other words, when the competence of the students has decreased, the load of the syllabus for them has increased, which is nothing but an irony.

\subsection{The Inappropriateness of Teaching Method}

To talk about the methodology that is being followed now for English literature teaching, the same thing can be told as has been said about the syllabuses. The very traditional system is being followed for teaching English literature in our country. In this system teachers are the central figures in the classroom who generally teach by delivering an 'information-packed' and 'scholarly' lecture on some particular topic or topics. Students in this process passively listen to those lectures and occasionally take notes on some important points. That is, importance is given to impaort/disseminate knowledge to students about various topics of literature and language, but no emphasis is given on enabling them to discover knowledge and ideas by themselves, or on developing their analytical capability, or on increasing their capacity to think about a particular matter from different perspectives, etc. They are not required to get involved in any kind of practice activities may it be on literary issues or on linguistic elements. They only receive knowledge from their teachers as much as possible. Referring to the present approaches to literature teaching Dutta (2001) says,

"These approaches may be viewed as a kind of 'dramatic monologue' in which the teacher is the only speaker and the students being 'passive recipients' rather than 'active agents' have got practically nothing to do other than listening to what the teacher says, no matter whether they understand it or not."

There may be some exceptions, but this is more or less the common picture in all the universities of the country. This very tradition of teaching literature has come down from generation to generation in our country, though the question 
about its effectiveness has been raised time and again.

\subsection{Lack of Teachers' Training and Research}

Speaking about the teachers, they do not get any training about how to teach effectively in the classroom. Soon after their appointment as teachers, they enter into the classroom to teach literature without any guidelines or expert advice. In this respect, they mainly depend on their past experiences about teaching them gathered as students from their teachers. However, as the beginning teachers they feel the experience of being possessed by anxiety and fear which come from their lack of pedagogical training, from their lack of insight in time-management, from their stage fright, from a sense of isolation, etc. Alam (2005) has given such a description of his own experience when he for the first time of his teaching career went into the classroom to teach English literature to the students of Dhaka University. Since they do not have any previous experience of handling a large audience, they feel embarrassed and uncomfortable when they go into a classroom for teaching. According to Showalter (2003, p.3), teachers of literature generally suffer from seven types of anxieties and among them lack of training in their profession is very remarkable. She opines that "Teaching is a demanding occupation, but few of us actually have studied how to do it." Having no previous training, they have not required confidence about how to utilize various activities possible in the classroom other than lecturing. When it is the normal practice in the educationally advanced countries that one must have the experience of working as a teaching assistant for some years before one is thought to be ready for real teaching, in our country there is no such provision. Again, when there is the provision of foundation/formal training for the newly recruited jobholders of all sectors including government schools and colleges, there is no such provision for the university teachers. As to the research activities, it is expected that the university teachers will go through the continuous research activities throughout their teaching profession and keep them always update in knowledge in their respective subjects or fields, but the overall scenario of the teachers of our universities is not like that. It is true that in the universities of our country, teachers do some research works, but they do it mainly for their quick promotion in the job. They require an $\mathrm{M}$. Phil. or a Ph. D. degree and/or a certain number of research publications for their promotion, and therefore, they do only as much research as are required for this purpose. Even in this respect to all the teachers are not equally honest. In many cases they just manage to get their required degrees or publications through unfair means. Moreover, once promotion is getting, most of them stop doing any research. What I want to argue is that research for intellectual development or professional development is not being done up to the expectation level.

\section{What should be done?}

For the effective teaching of English literature in our country, all the problems discussed above have to be addressed. However, the highest priority has to be given to improve as much as possible the linguistic conditions of the students who come to study this subject. If students are extremely deficient in English language, it becomes a very difficult undertaking to teach them literature of this language. I think it would be logical to argue that when the students are so badly lacking in language skills, English departments should take the initiative, along with teaching literature, for the improvement of their language skills. Otherwise, all the honest efforts of teaching them literature will go in vain. Therefore, many teachers now advocate for introducing language courses for newly admitted students as a remedial measure. Mentioning an incident of his department of Rajshahi University in the mid-70s in which some teachers showed their reservation for introducing a language course into the syllabus which was completely literature-based, Professor Aali Areefur Rahman (2008) relates that all the other teachers opposed this reservation, arguing that "since the secondary level of education was incapable of equipping our students with the necessary command over the language, it was up to the Department to teach even more intensive language courses." What I want to emphasize is that the English departments need to shoulder the responsibility of nursing the language skills of their students until or unless our educational institutions of lower levels are capable of providing them with linguistically competent ones. However, in order to take care of the language skills of their students what they need is to revise their syllabuses first.

\subsection{Revising the Syllabuses}

In the present realities, the syllabuses of the departments of English have to be thoroughly revised and this revision should be done mainly by (1) introducing a remarkable number of courses on language, (2) reducing the total number of literary texts and (3) increasing the works of non-native 
writers. Commenting on the necessity of revising the syllabuses of the English departments of the universities in Bangladesh, Islam (1986) in his 'Welcome Address' in a seminar on The State of English in Bangladesh Today held at Jahangirnagar University thirty years ago said,

"What is most concerning is that although in recent years the nature of the need of English has changed and the standard of teaching and learning it has gone down, we lethargically still continue to hold on to our old literary and highly intellectualized syllabus. The situation is simply unrealistic, to say the least."

Like Islam, Siddiqui (1986) too expressed his concern, in his 'Inaugural Address' at that seminar, regarding 'those students whose English is not adequate' and suggested for devising some means of helping them. And regarding these means, he drew the attention to adopt 'new courses, new approaches'. Ahmed (1986) has also given the same suggestions for bringing changes in the syllabuses of English literature that are taught in the universities of Bangladesh, and in this regard, he has emphasized on the consideration of "the needs as well as the abilities of the students who want to read the subject at the university level'. According to him, "The study of literature will be fruitless without an adequate linguistic sensitivity on the part of the students." Krishnaswamy and Sriraman (1995) also, referring to the Indian context, do not support the idea of preserving the highly classical syllabuses for the linguistically poor students.

According to many experts, language and literature are inseparable from each other. For appreciating or understanding literature one needs to be linguistically sound; similarly one will not learn the beauty of language unless one learns it in accompaniment with literature. In this regard, the view of Jakobson (1960, p. 377) is very much relevant--- "All of us here, however, definitely realize that a linguist deaf to the poetic function of language and a literary scholar indifferent to linguistic problems with linguistic methods, are equally flagrant anachronisms." Obviously, any attempt to teach literature neglecting the linguistic aspects will not bear any fruit. Criticizing the present approach of teaching literature by neglecting language, Moody (1983 cited in Dutta 2001) says that the existing system of the 'teaching of literature has faltered' and that in this system "students have been led busily but aimlessly through forests of inspired literary gossip."

In addition to the above considerations, the very purpose of students' coming to the English departments of our universities, especially, at the present time, should be taken into considerations. It is seen that, excepting a few, almost all of them come here with a hope of getting a good job after completing their studies. Since English is a very important international language and since any person who is good in English has a good prospect of getting a good job both in the local and the foreign job markets, they show more interest in the English language itself rather than in its literature. Only a very small number of them come with their love for English literature and want to be academic specialists or to build up their career in writing. Therefore, if their needs and goals are to be taken into account, attention has to be given to the vast number of the students whose prime goal is to achieve proficiency in English language in order to get a good job.

Therefore, what I want to argue is that the syllabuses of English departments should be revised, taking courses both from language and literature. That is, they should include, apart from the courses on literature, a remarkable number of courses on language to provide scopes to our students to remove their linguistic weaknesses. In the early stage or in the first four semesters after their admission, utmost attention should be given to develop their linguistic skills. Speaking alternatively, the syllabuses for Honors first and second years should include a number of language courses, which will deal with language structures, basic grammatical rules, language skills, phonetics, phonology, required aspects of linguistics, etc., so that our students can overcome their language deficiency to a great extent within this period. It is true that some of these courses are already present in the syllabuses of the English departments of most of the universities, but in many cases, they are not adequate and so the number of these courses has to be increased significantly.

Besides putting emphasis on the linguistic courses, significant changes should also be made with respect to the literary texts, by reducing their total number significantly. If the load of the textbooks is not so heavy, the students will feel much relieved and will not suffer from frustration. They will be confident and eager to read the original 
texts, instead of merely reading the notebooks. Again, apart from reducing the total number of books, the classical and canonical literary texts that appear to be intellectually and linguistically 'too heavy' to the students should also be replaced by such literary works as are student-friendly in terms of their language and ideas. In this regard, the works of the non-native writers should be given priority with emphasis on the writers of the Indian subcontinent. It is true that at present a mentionable number of works of the non-native writers, including those of the Indian sub-continent, such as, those of R.K. Narayan, Amitav Ghosh, Salman Rushdie, Joseph Conrad, Chinua Achebe, Arundhoti Roy, V.S. Naipaul, Nirad C. Chaudhuri, Wole Soyenka, etc., are found on the syllabuses of the English departments, but that number has to be increased further. It can be mentioned that the works of the non-native writers, especially those of the Indian subcontinent writers, will be more comfortable and understandable to our students as they will find the language of these works comparatively easy and will also feel familiar with the cultural elements of them. According to Kachru (1984), the language of the non-native literary texts get natively and modified on account of local influences and, therefore, learners see English as part of their culture.

Another point to keep in our mind is that the very purpose of learning English language or studying English literature in our country is 'functional', not 'integrative'. About the goal of the students coming to study literature, Littlewood (1964) opines that the students aiming at a functional command of a language may find a modern novel suitable for their purpose because of its linguistic contents, and that the students aiming at becoming future academic specialists may discuss the basic human issues portrayed in a classical play. Needless to mention that in our country literary texts have to be selected keeping in mind the first category of the students as mentioned by Littlewood. Commenting on the purpose of teaching English literature, Kachru (1984) says that in most of the non-native countries English is not taught to 'integrative' purpose, but for an 'instrumental' motivation. He, therefore, remarks that non-native English texts will be more appropriate for teaching English literature.

\subsection{Bringing Innovation into the Teaching Method}

The next thing to do is to bring innovation in the methodology of teaching literature. It has already been mentioned that a very traditional system is followed for English literature and language teaching in Bangladesh, with teachers transmitting knowledge and students passively receiving it. But this very process of teaching has to be changed, in order to get students involved in the teaching-learning process as much as possible. Talking about the importance of involving students in the classroom activities in teaching literature, Dutta (2001) says, "If students do not have the proper sense of belonging to and involvement in the class, the classroom activities are likely to be dull and non-rewarding." He has argued for an effective teaching methodology in which students will not remain passive, but actively participate in the learning process. However, Dutta has suggested a student-centered approach for this purpose, which, I think, will not solely be appropriate for teaching English literature in Bangladesh. It is true that there is no scope for disagreeing with his view that 'the maximum participation of the students' in the classroom activities should be ensured and that classroom should be made interactive, but the question can be raised about the appropriate means to achieve this end. It can be argued that a student-centered approach will not prove effective if the cultural and contextual realities of our country are taken into consideration. In the learner-centered approach, learners are required to take a lot of responsibilities upon their shoulders for their own learning-from deciding what they will learn and how they will learn to monitoring their own activities and promoting peer-correction (Brindley 1984, p. 15). But in our context, students do not like to take all these responsibilities upon their shoulders; instead they feel comfortable to learn under the control or guidance of their teachers. Therefore, it is not the student-centered approach; rather it is the teacher-centered approach that will be appropriate for the context of Bangladesh. In other words, our educational culture demands that everything in the classroom has to be done under the control of a teacher and it is true especially when the question of literature teaching is concerned. Speaking about English language teaching, Rahman (1999) says, "The culture of learner-centered, discovery-oriented tasks in the progressive tradition, much favored in communicative ELT circles today, apparently does not appear to suit the educational and socio-psychological ethos of learning in Bangladesh today." Shahidullah (1997, p. $124 \& 128)$ in an empirical study done at the higher secondary level of English education to know the teaching-learning culture of Bangladesh has found 
that the learners of Bangladesh want to learn under the guidance of their teachers. Even the teachers to believe that, students learn better when they learn under their control. In another study done on the teaching method of English language at the college level in Bangladesh, Wasiuzzaman (2012) finds that teachers here refuse to accept the view that language learning is students' responsibility. They think that it is mainly the teachers' responsibility to ensure students' learning, because "if the students are left on their own, they will hardly understand what is useful and what is useless for them." Students too, on their part, believe that teachers are the appropriate persons to take all the responsibilities for their learning. In addition to the cultural realities, the situational realities of our context, such as larger class-size and the heavy pressure of completing a syllabus and holding the examinations within a stipulated time are remarkable disadvantages in the way of following some of the principles of learner-centered approach.

Therefore, the teaching of English literature and language in our country has to be done by keeping the teachers at the centre of all classroom activities. These are the teachers who have to play the vital role of utilizing different kinds of techniques in order to involve the students into different kinds of tasks and activities and thereby make the teaching effective. They can make use of individual work, pair work, and group work or whole-class activities as the different techniques of involving the students in the learning process. For the whole-class activities, they can take an idea or a point from a text and then involve the students in a debate so that they get a practice of using English as well as can argue for their points from different perspectives. They can also properly utilize the techniques of asking students questions to elicit answers from them as well as encouraging them to ask questions. Through the use of these techniques, they can introduce a maximum amount of interactions between teachers and learners, between the texts and learners and also between the learners themselves. That is, they can get their students involved in the classroom discussions and thereby make them feel interested in the texts being taught. According to Showalter (2003, p. 55), experienced teachers develop their own classroom techniques and involve students in open discussion. Obviously, the participation of the students in the classroom activities; like debates, open discussions and answering or asking questions to develop their capabilities of analytical, critical and free thinking.
They get a practice of judging a point from different perspectives as well as an opportunity for promoting their imaginative faculty. Therefore, what a teacher needs to do is to put emphasis on active learning, adopting one kind of dialogue and problem-solving pedagogy.

However, the teaching has to be done from the perspective of an integrated approach. That is, the teaching of literature should be integrated with the teaching of language. According to Carter (1982, p. 12), "The integration of language and literature teaching in English classrooms is a long overdue." Collie and Slater $(2087$, p. 10) too have expressed the similar view and have suggested that the approach to the teaching of literature should be to let the students derive the benefits of communicative and other activities for language improvement within the context of suitable works of literature. Therefore, while teaching a literary text, teachers should focus on both the linguistic and literary aspects of the texts.

In dealing with a literary text, the first thing that teachers need to do is to make use of some warm-up activities whenever they will go to teach a new text or a new item to rouse curiosity in the minds of the students about it. According to Collie and Slater (1982, p. 16), the first encounter of the students with a literary work is very crucial as their first impressions can color their feelings about the whole enterprise they find themselves engaged in.' Therefore, teachers, according to them, with the help of warm-up activities need to draw the students quickly to text so that they can find it interesting and want to continue reading it on their own. Once the necessary interest or curiosity about the new text is roused in the minds of the students, teachers find it easy to deal with the text. To utilize their interest and curiosity, they can assign some sections or parts of the text to the students for home-reading and can deal with the other sections or parts in the classroom. In this respect, what is required by teachers is to verify students' home-reading duly and then relate the parts of the text assigned for home-reading to the parts dealt with in the classroom. In this process, they can cope with their time constraint and can involve their students in the teaching-learning process.

\subsection{Developing Teachers' Competence}

It has already been discussed above that the university teachers in general in Bangladesh are conspicuously lacking in training on teaching 
pedagogy, in the one hand, and suffering from inadequacy in their research activities, on the other hand. But for the effective teaching of literature and language, there is no alternative to the trained, skilled and knowledgeable teachers. Without them, all other efforts relating to the revision of the syllabus or the amendment of the teaching method will come to no use. Only the skilled, dynamic, pedagogy conscious and knowledgeable teachers can make the classroom effective and achieve the target results. Therefore, for developing the university teachers as the skilled, competent, pedagogy conscious and resourceful manpower for teaching, emphasis should be given to their training and research. As to training, it can be said that through training a teacher can acquire applied and new knowledge to develop his/her professional skills and knowledge. In other words, he/she can develop further skills and techniques to do his/her professional job more effectively. According to Richards (1990), to be a successful teacher one needs to combine two kinds of knowledge-one is theoretical and another is practical. Training helps one to bring these two kinds of knowledge together to do classroom activities properly. Therefore, it can be said that training plays a vital role to handle the classroom activities competently. As teaching is regarded as a skill that can be achieved, there should be continuous efforts on the part of a teacher to develop himself or herself as a good teacher, and undoubtedly training can help him/her a lot in this regard. For teachers' development at the university level, there should some institutes or training-centres, manned by education experts, to provide training to teachers so that they can improve their teaching skills. Referring to this point, Haseeb (2005) reports, "Most universities in North America have their in-house centers/institutes specifically aimed at fostering excellence in teaching among their teachers. These centers conduct workshops and training programs in teaching which benefit faculty members at all levels." Focusing on the necessity of formal training, he opines that the need for the formal training of university teachers in pedagogy is now increasing day by day, which is being recognized in all universities around the world.

Talking about the importance of research, Showalter (2003, p.11) opines that research and teaching at the university level are complementary and that a good teacher is the one who continues doing research for his/her self-development and to keep himself/herself update in the latest development of knowledge in the subject he/she teaches and also in the teaching methodology, along with teaching. Since research activities make a teacher a knowledgeable and resourceful person, he or she develops more confidence in his/her teaching. Actually, research helps us achieve dependable knowledge through the scientific and the systematic process and enable us to apply that knowledge effectively to the problems of teaching and learning within the formal educational framework. Referring to the definition and significance of research, Mouly (1978 cited in Cohen and Manion1994, p. 40) writes,

Research is best conceived as the process of arriving at dependable solutions to problems through the planned and systematic collections, analysis and implementation of data. It is a most important tool for advancing knowledge, for promoting progress, and for enabling man to relate more effectively to his environment, to accomplish his purposes and to resolve his conflicts.

If we take the definition of Mouly into consideration, we can say that research can do a lot for us as the context of Bangladesh has its own peculiarities and own problems.

However, a successful teacher, besides taking training and doing research, has to be aware of some other requirements. He or she will ignite the students' thirst for knowledge and inspire them to read more and more. According to Showalter (2003, p. 25), the objective of a teacher is not to cover a certain set of topics, but to facilitate students' learning. She stresses on the fact that a good teacher will maintain the right balance between imparting information and making students think. She advocates the idea that the main goal of teaching should be to inspire students to be critical thinkers. In this regard, she makes a reference to Wilbert J. McKeachie (1999) who comments that "the objective of a course is not to cover a certain set of topics, but rather to facilitate student learning and thinking." To speak about the other qualities, an effective and successful teacher needs to be friendly with his or her students, sharing ideas with them so that teaching becomes enjoyable and memorable. Moreover, he or she will be technology-friendly and make the proper use of modern technologies such as videos, films, multimedia, etc. in the classroom.

\section{Conclusion}


The English departments of the universities of Bangladesh have a long tradition in our country and have always made remarkable contribution to produce skilled and enlightened professionals and citizens of the country. But at present these departments are beset with problems in four major areas relating to the teaching-learning activities. On the one hand, the teaching method and the syllabuses that are being followed have become outdated and ineffective in view of the new pedagogical developments and students' needs. On the other hand, students' competence in the English language and teachers' competence in their professional performance have drastically fallen. Students are getting admission to English departments without the required proficiency in English, and teachers are teaching without proper training in their profession. Moreover, they are showing reluctance in research activities, which prevents them from their intellectual development. All these problems have made it difficult for effective teaching-learning practices in these departments. In order to get rid of this situation, it is urgently required to address all these problems properly and put these departments on the right track. It is needless to mention that a concerted effort is needed in this regard and all concerned, such as, the teachers of English Departments, the university authorities, the government of Bangladesh, etc., should come forward.

\section{References}

Ahmed, A. "Suggestions for the Reorganization of

English Studies in the Universities of Bangladesh." In Dr. Nurul Islam and Shafi Ahmed (eds.),The State of English inBangladesh Today (A Collection of Seminar Papers and Proceedings of the First Convention of English Association of Bangladesh Held at Jahangirnagar University on June 12 \& 13, 1982).Dhaka: English Association of Bangladesh, 1986. pp. 24-30.

Alam, F. "The Dhaka University English Curriculum: A Decade of Development." In Fakrul Alam, Niaz Zaman and Tahmina Ahmed (eds.), Revisioning English in Bangladesh. Dhaka: The University Press Limited, 2001. pp. 1-14.

Alam, F. "The Joys and Anxieties of Teaching English Literature." The Daily Star. Dhaka, 11 June, 2005.

Amin, R . "Developing Reading Skills through Effective Reading Approaches". InternationalJournal of Social science and Humanities, 2019. 4(1), pp. $35-40$.
Brindley, G. Needs Analysis and Objective Setting in the Adult Migrant Education Program. Sidney: NSW Adult Migrant Education Service, 1984.

Carter, R. Language and Literature. London: Allen Unwin, 1982.

Choudhury, Serajul Islam. "Rethinking the Two Englishes." In Fakrul Alam, Niaz Zaman and Tahmina Ahmed (eds.), Revisioning English in Bangladesh. Dhaka: The University Press Limited, 2001. pp. 15-26.

Chowdhury, Kabir. "The State of English in Bangladesh." In Dr. Nurul Islam and Shafi Ahmed (eds.), The State of English in Bangladesh Today (A Collection of Seminar Papers and Proceedings of the First Convention of English Association of Bangladesh Held at Jahangirnagar University on June 12 \& 13, 1982). Dhaka: English Association of Bangladesh, 1986. pp. 13-23.

Cohen, Louis and Lawrence Manion. Research Methods in Education. London: Routledge, 1980. (4thed,). 1994.

Collie, Joanne and Stephen Sater. Literature in the Language Classroom. Cambridge: Cambridge University Press, 1987.

Dutta, Sujit K. "English Language and Literature in Bangladesh: Towards a Methodology." InFakrul Alam, Niaz Zaman and Tahmina Ahmed (eds.), Revisioning English in Bangladesh. Dhaka: The University Press Limited, 2001. pp. 122-140.

Haseeb, Dr. A S M A. "Achieving Excellence in Classroom Teaching in Our Universities." The Daily Star. Dhaka, 5 April, 2005.

Slam, Dr. Nurul. "Address of Welcome." In Dr. Nurul Islam and Shafi Ahmed (eds.), The State of English in Bangladesh Today (A Collection of Seminar Papers and Proceedings of the First Convention of English Association of Bangladesh held at Jahangirnagar University on June 12 \& 13, 1982). Dhaka : English Association of Bangladesh, 1986.

Jakobson. R. "Closing Statement :Linguistics and Poetics." In T. Sebeok (ed.), Style in Language. Mass: MIT Press. 1960.

Jalil, Md. Abdul."Problems of B. A. Pass Compulsory English and Related Matters." In Dr. Nurul Islam and Shafi Ahmed (eds.), The State of English in Bangladesh Today(A Collection of Seminar Papers and Proceedings of the First Convention of English Association of Bangladesh Held at Jahangirnagar University on June 12 \& 13, 1982).Dhaka : English Association of Bangladesh, 1986. pp. 84-93.

Kachru, Biraj B. "Non-native Literatures in English as a Resource for Language Teaching." In 
Christopher Brumfit and Ronald Carter (eds.), Literature and Language Teaching. Oxford: Oxford University Press, 1984. pp.140-149.

Littlewood, William T. "Literature in the School Foreign Language Course." In Christopher Brumfit and Ronald Carter (eds.), Literature and Language Teaching. Oxford : Oxford University Press, 1984. pp.177-183.

McKeachie, Wilbert J. Teaching Tips: Strategies, Research and Theory for College and University Teachers, $10^{\text {th }}$ edition. Boston: Houghton Mifflin, 1999.

Moody, H.L.B. "Approaches to the Study of Literature: A Practinioner's View." In Brumfir, C. J. (ed.), 1983.

Rahman, Aali Areefur. "English Studies in RajshahiUniversitty: Background, Current Status and Future Prospects." Praxis, Journal of the Department of English, vol. 3.Rajshahi: Rajshahi University. 2012, pp. 5-11.

Rahman, Arifa. ELT Innovation and Cultural Change: A Bangladeshi Perspective. A paper presented in an international conference held at the British Council, Dhaka from January 31 to February 2, 1999.

Rahman, Hamidur. "English Language Teaching in Bangladesh: Didactics on the Pragmatics of a Foreign Language Teaching Policy". (A paper presented in an international conference held at the British Council, Dhaka from 31 January to 2 February, 1999).

Richards, J. C. and D. Nunan. Second Language Teacher Education. Cambridge: Cambridge University Press, 1990.

Richards, J.C. The Language Teaching Matrix. Cambridge: Cambridge University Press,1990.

Shahidullah, M. Teaching-Learning Culture in Bangladeshand Recent ELT Theories: Confrontation and Contradiction. Unpublished Ph.D. Dessertation, University of Pune, India, 1997.

Showalter, Elaine. Teaching Literature. Oxford: Blackwell Publishing, 2003.

Siddiqui, ZillurRahman. "Inaugural Address."In Dr. Nurul Islam and Shafi Ahmed (eds.), The State of English in Bangladesh Today (A Collection of Seminar Papers and Proceedings of the First Convention of English Association of Bangladesh Held at Jahangirnagar University on June 12 \& 13, 1982). Dhaka: English Association of Bangladesh, 1986. pp. 9-12.

Wasiuzzaman, M. 'Teachers' and Students' Roles in English Language Classrooms in Bangladesh: Some Beliefs." Praxis, Journal of the Department of English, vol. 4.Rajshahi: Rajshahi University.2012, pp. $145-165$. 